\title{
El asombroso razonamiento de los niños
}

\author{
Jorge Salgado Sanhueza \\ Universidad de La Serena, La Serena, Chile. Email: jsalgado@userena.cl
}

\begin{abstract}
Resumen: ${ }^{1}$ Muchas veces, los niños nos asombran con razonamientos elaborados con una lógica impecable, limpia y hermosamente planteada. Otras veces, no los entendemos y sus comportamientos nos parecen absurdos por sus pataletas, sus dichos o sus juegos que calificamos: "son cosas de niños”. De igual modo, no entendemos las situaciones de injusticia que cometemos y que exponemos a los niños a una comprensión brutal, dura e implacable entre la conclusión diáfana de su razonamiento y las reglas sociales y económicas que le imponemos y que ellos no entienden. Así los vamos incorporando a una sociedad "justa” y "buena” que el niño no entiende y que, más tarde debe aceptar. Una lucha ocurre entre su "razón natural” y su "razón social".

Palabras clave: Razonamiento formal de los niños, Modus Ponens y Modus Tollens, contexto del razonamiento infantil, principio de identidad en el juego infantil.
\end{abstract}

\section{The amazing reasoning in children}

\begin{abstract}
Many times, children amaze us with reasoning developed with an impeccable logic, clean and beautifully raised. Other times, we do not understand their behaviors and their conducts seem to be absurd because of their tantrums, sayings and games that we qualify: "they are kids stuff". Similarly, we do not understand the situations of injustice that we commit and through which we expose children to a brutal, harsh and relentless understanding between the diaphanous conclusion of their reasoning, and the social and economic rules that we impose and they don't understand. Thus we incorporate them to a "fair" and "good" society that the child does not understand and that, later, he must accept. A fight takes place between his "natural reason" and his "social reason".

Key words: Formal reasoning in children, Modus Ponens and Modus Tollens, context of child reasoning, principle of identity in children's games.
\end{abstract}

\section{O surpreendente raciocínio das crianças}

Resumo: Muitas vezes, as crianças surpreender-nos com argumentos feitos com uma lógica pura, limpa e muito bem colocada. Outras vezes, não os entendemos e seus comportamentos parecem absurdos pelos seus acessos de raiva, suas palavras e brincadeiras que qualificamos como: "São coisas de criança”. Da mesma forma, nós não entendemos as situações de injustiça que cometemos e expomos às crianças a uma compreensão brutal, dura e implacável entre a conclusão clara de seu raciocínio e as regras sociais e econômicas que impomos, e que eles não entendem. Assim, vamos incorporando a uma sociedade "justa" e "boa" que a criança não entende e que depois deve aceitar. Uma luta entre sua "razão natural” e sua "razão 
social”.

Palavras-chave: raciocínio formal das crianças, Modus Ponens e Modus Tollens, contexto do raciocínio infantil, princípio de identidade nas brincadeiras infantis.

Muchas veces los comportamientos o expresiones verbales de los niños desconciertan a los adultos. Las "pataletas", las respuestas "inverosímiles” no parecen tener una coherencia lógica, actitudes inauditas que no se comprenden de acuerdo a los antecedentes que se manejan. Sin embargo, un examen más detenido, de acuerdo a un contexto donde se producen las emisiones verbales o las situaciones, muestra todo lo contrario.

Las "razones" de los comportamientos de los niños y sus formas argumentativas están determinadas por reglas formales que emplean los adultos en sus tareas cotidianas o en las actividades profesionales. Los niños -que hemos sido todos- emplean razonamientos que impresionan cuando expresan verbalmente sus conclusiones o mediante actitudes, comportamientos que obedecen a formas lógicas construidas en forma innata (MKcCormack, 2013)

Los niños presentan un pensamiento complejo que se manifiesta mediante empleo de reglas de razonamiento como Modus Ponens, Modus Tollens, analogías, etc.

Esta característica formal y compleja del pensamiento de los niños ha sido analizada por Mathew Lipman (Lipman, 1991). Desde la primera infancia, los niños poseen procesos de investigación, razonamiento, organización y traducción de la información en sus formas más simples. Establece que las habilidades de "investigación" es una práctica autocorrectiva mediante tanteos, aproximaciones, descubrimientos. Asimismo, las habilidades de razonamiento, de información, organización, deducción se expresan lingüísticamente mediante formas básicas de agrupación de la información: oración, el concepto y esquemas (una narración, una historia)

Siguiendo esta línea de investigación y los planteamientos de Lipman con relación al pensamiento complejo de los niños, manifestándose en la praxis educativa a través de la Filosofía para niños (libros Kio y Guz,Pixy, Ari, etc.) es posible sostener que el pensamiento de los niños presenta estructuras lógicas más complejas que simples analogías. En investigaciones realizadas en Universidad de La Serena acerca del aprendizaje informal de los niños (Salgado, Calvo, \& Catalán, 1998) se encontraron razonamientos formales de predicados de primer orden (Predicados monádicos) y de segundo orden (Predicados poliádicos) en las expresiones orales de los niños. Algunas de estas expresiones formales como el Modus Ponens (Si p entonces q. Y si p, por lo tanto, q) o el Modus Tollens ( Si P entonces Q. No es el caso que Q. Por lo tanto, no P) aparecen en situaciones cotidianas, fuera de la sala de clases. 
En investigaciones posteriores (Salgado Sanhueza, 2012) se han obtenido resultados que permiten afirmar con más precisión y detalle acerca de la complejidad del pensamiento de los niños, especialmente en el aspecto del razonamiento lógico entre 4 y 8 años. En este proceso, se emplearon se utilizaron registros etnográficos verbales y visuales (videos) de conversaciones, acciones y juegos de los niños en diferentes contextos: la sala (jardín infantil), el patio de recreos, juegos. Se utilizó el software Atlas.ti, vers.6.2 para analizar los datos e inferir explicaciones mediante el procedimiento de la Grounded Theory. Los registros analizados corresponden a los años 2011 y 2012 en cuatros jardines infantiles correspondientes a La Serena, Coquimbo en Chile.

Las observaciones empíricas y el análisis de registros verbales, juegos, expresión corporal, gestos permiten establecer que el pensamiento regulado formalmente está presente en esas expresiones de una manera más regular y compleja que asombran por su estricta conexión entre premisas y conclusiones que, muchas veces, los adultos no comprenden o no se percatan, generando incomprensiones, castigos, diferencias socio-económicas con graves repercusiones en la educación formal de la escuela.

Desde una perspectiva formal, entendiendo por ello el aspecto sintáctico subyacente en expresiones verbales emitidas por los niños, los razonamientos se caracterizan mayoritariamente por una forma tradicional y básica del Modus Ponens y Modus Tollens muy frecuente en los adultos. Hay muchas expresiones lingüísticas empleadas por los niños mientras juegan, o responden ante situaciones generadas en la sala de clases (jardín infantil, en el patio, en el recreo, etc.) que mantienen estas formas básicas de razonamiento.

\section{Por ejemplo en el siguiente caso: ${ }^{2}$}

“Margarita grita; luego le dice a x "gritemos" -no puedo- por qué porque me sacaron una muela- y cómo te la sacaron -con una llavey qué te pasa si gritai* -me duele la muela.

P 1: F11 a LSC AP 001.rtf - 1:10 [Ámbar grita ; luego le dice a ..] (76:77) [Relación antecedente y consecuente - Family: Tipos de razonamiento]

La estructura de este razonamiento es la siguiente: Si P entonces Q. P. Por lo tanto, Q.

$\mathrm{Al}$ analizar esta expresión, se obtiene el siguiente razonamiento: "Si grito, entonces me duele la muela. Grito. Por lo tanto, me duele la muela”. Además, el contexto de este razonamiento señala que la niña, $\mathrm{X}$ da una razón por la cual ella no puede ejecutar la acción de gritar solicitada por Margarita. También aparece la analogía del instrumento del dentista: "una llave". Es la asociación de un elemento conocido por otro desconocido, más familiar y comprensible para la niña. La conclusión es impecable. 
En otro Razonamiento, con una conclusión sorprendente por los alcances metafóricos y poéticos para los adultos, pero lógica para un niño:

"Rosita encuentra un tallo y Paula lo arranca, Rosita le dice a la practicante: la Paula mató una flor”.

P 2: F11 a LSC AP 002.rtf - 2:6 [Rosita encuentra un tallo y A..] (48:48)

[Razonamiento por modus ponens - Family: Tipos de razonamiento]

La forma del razonamiento es un Modus Ponens que se reconstruye de la siguiente manera:

"Si se arranca del tallo a una flor, entonces se mata la flor. Ámbar arranca el tallo. Por lo tanto, Ámbar mató la flor”.

Esta conclusión, aparentemente sorprendente, no es sorpresiva. Es el resultado de un razonamiento estructurado formalmente y asociado semánticamente con un contenido significativo para una niña, Alondra. En este caso, el rasgo semántico es asociar "flor” (vegetal) con ‘ser vivo'. La conclusión de este razonamiento está ligada al hecho de "matar", es decir, privar de vida a una flor, arrancándola del tallo.

Otro registro muestra la complejidad del razonamiento con el empleo del cambio semántico del antecedente sin repetir la negación formal. Parece una expresión que sólo intenta negar una afirmación formulada por la profesora pues el niño se siente menoscabado.

“A la educadora se acerca un niño y antes de que él le hable la tía le dice: "¡Oiga, yo pasé en el colectivo allá afuera recién, y lo vi a usted llorando! ¿Qué le pasó?" El niño la mira frunciendo el ceño y le dice: "¡Mmm, no tía!" La educadora le dice: "Estabas con una señora y un niño, y tú te tocabas el zapato y llorabas". El niño le dice: "¡Ah, entonces era otro niño!” La educadora, la madre y la asistente ríen, y el niño dice: "¡No si es verdad, porque yo sólo lloro en mi casa!" (F11bCQCSPA 008.doc)

Se interpreta del siguiente modo: "Si me ven llorado en mi casa entonces soy yo. Me ven llorando fuera de mi casa. Por tanto, no soy yo". (Si P entonces Q. No P. Por lo tanto, no Q). Este razonamiento, planteado como antítesis a la afirmación de la profesora (la tía), concluye sosteniendo que el niño observado por ella es otro. Esta conclusión se basa en un hecho "Yo sólo lloro en mi casa”. La profesora vio a un niño llorando en un lugar público (no en la casa del niño). Entonces no era él. La conclusión es sorprendente, basada en un antecedente verdadero para el niño.

El siguiente diálogo muestra una complejidad formal que asombra, puesto que no sólo plantea una estructura lógica, sino que además señala un contenido de carácter semántico. Es importante la argumentación retórica que emplea la niña al acudir al argumento ad verecundiam, colocando a la "tía” (Educadora) como autoridad veritativa. 
“-Si tú me enterrai esa abuja sale sangre y te podi morir.

-No no la tía dijo que uno si se entierra la abuja se hace una hería’ pero no se muere".

[P 2: F11 a LSC AP 002.rtf - 2:11 [: no no la tía dijo que uno si..] (75:75)

La forma implícita del razonamiento es más o menos la siguiente: "Si me enterrai esa abuja entonces sale sangre y te podis morir”. Además de ser un razonamiento encadenado, la conclusión es modal "Podis". Esta modalidad, señala un razonamiento que tiene un valor veritativo de trivalencia (Verdadero, Falso, Ni verdadero ni Falso (posible)). Desde un punto de vista formal, se está en presencia de un razonamiento "difuso" que sale del margen de una lógica bivalente, usualmente empleada en el Jardín Infantil. Además de ese razonamiento difuso, está el razonamiento contrario, que pretende negar la afirmación anterior. En definitiva, hay un esquema argumentativo. El argumento de ad verecundiam, lo dicho por "la tía" (Educadora de párvulos) pareciera zanjar la discusión

Muchas veces estos razonamientos y argumentos pasan desapercibidos, considerándolos sólo como arranques emocionales como en el siguiente caso:

«La mamá de Angélica la llama al celular de la educadora, conversan delante de todos en la sala, se quedan callados(das), las miradas se dirigen a Angélica, ella estira la boca mira para todos lados se pone rígida y con una mano comienza a jugar con su falda (luego cuentan que hoy su mamá la tuvo que mandar con otra mamita ya que ella no alcanzaba venir a dejarla, ella lloró diciendo que ella quería venir con su mamá, llegó llorando hasta la puerta del colegio). Pedro y José aplauden y dicen: !bravo! (cuando Angélica está hablando con su mamá)».

(P 4: F11 a LSC AP 004.doc - 4:1 [La mamá de Angélica la ..] (6:8)

En este registro, se puede constatar el alto contenido emocional de los niños. El llanto de Angélica y la alegría de Pedro y José. Además de esta característica, reflejada en la transcripción, hay una explicación de estas reacciones. Ella está en el tipo de razonamiento que genera estas conductas. Es un enlace de proposiciones que termina con la alegría: Si Angélica no conversa por teléfono con su mamá entonces se entristece y llora. Y si llora, Pedro y José se entristecen. Angélica conversa con su mamá y se alegra. Y si se alegra, entonces Pedro y José se alegran. Si se alegran, dicen ¡Bravo! Esta secuencia lógica permite comprender que la alegría de los niños es causada porque Angélica logró hablar con su mamá.

Otro tipo de razonamiento, más complejo que los anteriores, es el Modus Tollens empleado por los niños de un modo natural. Este tipo de razonamiento es más complejo debido a dos negaciones. Al negarse el consecuente, se niega el antecedente (P entonces Q. No P. Por lo tanto, no $\mathrm{Q}$. 
«( Observa un mural marino del colegio) los tiburones muerden abren la boca y tienen dientes grandes, los peces no muerden no tienen colmillos.»

\section{P5: F11 a LSC AP 005.doc - 5:14 [( observa un mural marino del ..] $(137: 137)$}

Este razonamiento se ordena se la siguiente manera:

"Si los peces muerden, entonces tienen colmillos. Pero, los peces no tienen colmillos. Por lo tanto, no muerden”.

Este razonamiento, hecho por analogía encierra una complejidad mayor. La relación entre ambas proposiciones está en la propiedad de "morder". Quien muerde tiene colmillos. (Como es el caso de los tiburones). Sin embargo, los peces no tienen colmillos. La conclusión aparece con gran claridad y consecuencia: los peces no muerden. Independientemente de la verdad de la aseveración, lo sorprendente radica en la estricta lógica del razonamiento. Al negarse el consecuente, se niega el antecedente..

En el siguiente ejemplo, Una niña, Anita, pregunta si sus zapatillas se encienden. Ximena, su amiga, le responde diciéndole que si se golpea las zapatillas(a las ampolletas) y éstas se encienden, entonces tienes luces. Ella realiza el "experimento", golpeando las zapatillas. Como no se encienden, entonces se muestra que no tienen luces:

"Anita: ¿Prenden las luces?

Ximena: No. No tienen (empuña su mano y comienza a pegarle a la zapatilla). No ves que no prenden”.

Este enunciado, ordenado formalmente es el siguiente:

"Si las zapatillas tienen luces entonces al golpearlas se prenden (encienden). Las zapatillas no se prenden al golpearlas. Por lo tanto, no tienen luces.”

El razonamiento no es fácil de entender formalmente debido a la complejidad de la conclusión, al empleo de una prueba fáctica y al empleo de los términos.

En este contexto, hay un tipo de razonamiento que tiene una cualidad de rechazar una aserción mediante el recurso empírico. Los niños muestran esta habilidad para refutar enunciados mediante afirmaciones empíricas referidas a sus propias experiencias o pruebas dadas por personas mayores que tienen importancia para ellos. Por ejemplo: experiencia personal, la educadora de párvulos, la mamá, abuela, etc.

lla.

En la sala de clases se acerca Ámbar a mi cara y me apunta la espini- 
Amapola: ¿qué tení ahí? ¿Es un lunar?

- Es una espinilla

Amapola: ¿qué hace eso?

-Salen por comer mucha grasa ejemplo: mantequilla, mayonesa.

- yo como toda la mantequilla, y no tengo (se toca la cara) a ver dime

tú (me muestra su cara) ¿tengo yo tengo de eso?

P 5: F11 a LSC AP 005.doc - 5:20 [En la sala de clases se acerca..] (203:208)

El razonamiento propuesto es el siguiente: "Si como mantequilla, mucha grasa o mayonesa, entonces me salen espinillas”

Amapola, la niña, ofrece una prueba empírica: "Yo como toda la mantequilla y no tengo (espinillas)”. La refutación mediante el recurso empírico, permite alternar esta forma de razonamiento con la forma lógica. Desde esta perspectiva, aparece un claro empleo de la "causalidad" que permite explicar estas inferencias, tanto formales como empíricas. En este caso se puede plantear esta forma de razonamiento, regulado causalmente:

"Si como mantequilla entonces me salen espinillas"

"El comer grasa, mantequilla, mayonesa es la causa de la aparición de la espinilla”

Como bastante mantequilla y no tengo espinillas.

Por lo tanto, comer mantequilla no es la causa de la aparición de espinillas.

A una proposición que plantea un estado de cosas, la niña presenta otro estado de cosas que contradice el enunciado de la persona observadora.

Otro aspecto interesante que presentan los razonamientos de los niños, está relacionado con el principio de causalidad, como se ejemplifica en el caso anterior. Esta característica parece explicar el empleo de formas lógicas como el Modus Ponens y Modus Tollens y al mismo tiempo, asombra que puedan establecer predicados poliádicos. Junto con el empleo de la causalidad y sus propiedades, está la formulación de una hipótesis y de un valor veritativo de 'probable' (trivalente).

Pedro: (dirigiéndose a la educadora) ¡tía tía, la María vomitó!.

(Isabel, Jenifer, Nina, Jorge miran a María, Isabel con la boca abierta pone sus rodillas sobre la silla , y mira atentamente cuando la llevan al baño)

Jorge: quizás le hizo mal la leche de chocolate o la galleta.

P 5: F11 a LSC AP 005.doc - 5:16 [Pedro: ( dirigiéndose a la e..] (173:175) 
El niño, producida una acción (vomitar), la relaciona como un efecto producido por una causa (hacerle mal la leche o la galleta). Además, esa formulación de hipótesis está recalcada por la afirmación "Quizás". Nuevamente aparece el valor veritativo trivalente.

La causalidad, A es causa de B, es un argumento bastante empleado por los niños, especialmente porque tiene una connotación empírica. En este caso, la causa que María haya vomitado es "quizá le hizo mal la leche con chocolate o la galleta”. Este principio aparece frecuentemente como forma de hipótesis que los niños intentan falsear empíricamente. En el caso de José con María, el niño buscó, molestó y solicitó encarecidamente que le dieran permiso para ir a la Enfermería donde llevaron a la niña. Las “tías” no escucharon a José. Incluso, amenazaron con castigarlo si seguía insistiendo y molestando saber si la leche que le habían dado en el Jardín Infantil habría sido la causa del vómito.

Hay otros elementos que condicionan no sólo el razonamiento sino también la perspectiva óntica de los niños, hecho que permite vivir una realidad que para los adultos es una ficción, un mundo imaginario.

Uno de estos elementos y quizá uno de los más importantes es el principio de identidad que aparece especialmente en los juegos infantiles, donde se vive una realidad determinada por el principio de identidad, $A=B$, 'A es idéntico a B'. Por ejemplo, Juanito se identifica con el león. Juanito es un león (Juanito es un león. El león es Juanito). En un universo discursivo donde se produce la identificación, las acciones y los pensamientos son "mágicos", es decir, las acciones son reales por identificación. En el siguiente ejemplo, que ocurrió en la sala del Jardín Infantil, se observó lo siguiente:

Registro (El contexto del razonamiento)

"Pedro acusa a Angélica de haberlo mordido

Angélica comienza a mover sus rodillas y a mover la lengua dentro de su boca

Educ.: No tengo animales en la sala ¿Angélica qué te hizo el Pedro? Angélica: mira a la educadora pero no responde nada

Educ: Isabel tú estabas ahí. Cuéntame Pedro le hizo algo, porque me extraña que Angélica lo muerda.

Isabel: yo estaba con ellos y la Angélica lo mordió, Pedro no le hizo nada.

Angélica: se lleva las manos a la boca juega con sus labios, tiene los ojos llorosos, no habla

Pedro: Yo no le hice nada

Educadora: se queda señorita Angélica sin recreo.

Angélica no se mueve está sentada y observa a la educadora.

La educadora conversa con la asistente sobre sus dudas, no le calza que Angélica haya tenido esa reacción por nada. Luego dice y tú Pedro también te quedas sin recreo para que se acuerde de lo qué pasó. 
Al rato todos salen a recreo menos ellos, Angélica callada, Pedro dice es que estábamos jugando a los leones yo la mordí y ella me mordía (se toca las manos mientras cuenta).

La educadora deja que ambos salgan a recreo después de que Pedro contara la verdad."

\section{(P 5: F11 a LSC AP 005.doc - 5:19 [Bastián acusa a Scarlet de hab..]} (189:201))

$\mathrm{Al}$ analizar esta situación hay un elemento importante para dar sentido a esta acción de los niños y a la reacción de la "tía": Simplemente, los niños jugaban “a los leones”.

En este contexto, Pedro acusa a Angélica de haberlo mordido. La niña adopta una actitud "rara": mueve las rodillas y la lengua dentro de la boca. Isabel, otra niña, requerida por la profesora ratifica que Angélica mordió a Pedro. La Profesora, sin comprender esa "realidad mágica”, el contexto lúdico de los niños, castiga a Angélica. También castiga a Pedro. Finalmente, éste, le cuenta a la profesora que jugaban a los leones.

Este principio, aparentemente formal, se yuxtapone a un contexto dado, hecho que transfiere un contenido, una semántica. Este grado de significación, donde hay un mundo lleno de sentido, donde operan todas las relaciones imaginables e identidades. Quizá esa sea la razón por la cual, nosotros, seres humanos, transferimos las connotaciones "reales" más las "connotaciones" imaginarias, a un mundo pleno, idéntico al que vivimos “realmente”. Es el mundo de Peter Pan, de La Tierra de Nunca Jamás. Esa transferencia de lo real a lo imaginario nos lleva a otro nivel ontológico, los entes imaginarios. ${ }^{3}$

Esta anécdota revela algo: el contexto "mágico" de los niños está regido por el principio de identidad de $\mathrm{A}=\mathrm{B}$ opera de un modo efectivo. Por tanto, en ese "mundo de identidades" los razonamientos operan igualmente, aunque en otro contexto semántico al de los adultos.

Otro aspecto semántico interesante y frecuente, es el empleo de la analogía que se traduce en una relación significativa entre dos o más elementos que permite establecer nexos de similitud o diferencia. Por ejemplo, las analogías lúdicas, donde, a veces, funcionan como identidades.

La analogía “A es como B” funciona en un contexto de juego. El siguiente ejemplo, muestra esta característica:

"Margarita: pone las manos debajo de la mesa ....tía a usted le gusta jugar mucho en el poputador"

P 2: F11 a LSC AP 002.rtf - 2:4 [Margarita: pone las manos debajo ..] (38:38)

Margarita, niña, quien coloca las manos debajo de la mesa como si escribiese en un computador. Esa acción la relaciona con el juego. De esta 
manera, al preguntarle a la persona que transcribe observaciones (etnógrafa), hace una analogía con el juego. La analogía es la siguiente "Así como yo juego con el banco a teclear, así la etnógrafa, juega en el computador”. Esta analogía, opera del siguiente modo A es a B como A es a C.

En este contexto lógico, la analogía puede explicar el empleo de la metáfora que aparece normalmente en las expresiones infantiles. Por ejemplo:

“¡veo agua ¡¡están regando el cielo i

Están mojando el patio”.

P 3: F11 a LSC AP 003.doc - 3:1 [iveo agua ¡iestán regando el c..] (5:6)

Así como riegan el patio, así riegan el cielo. La metáfora radica en la analogía de lanzar agua al cielo como lanzar agua a la tierra (el patio), pues el cielo se refleja en el agua.

Otro tipo de analogía es la relación que establecen los niños con elementos concretos, percibidos directamente que, en muchos casos, adquiere una connotación alegórica. Por ejemplo, un conjunto de lápices de colores puede representar una familia. El lápiz más grande y grueso representa al papá, el siguiente en estatura y más delgado, la mamá y así sucesivamente hasta llegar a los más pequeños que son los hijos.

"Ponen todos al centro de la mesa los lápices, comienzan a decir tú eres el papá, yo la mamá, tú la hija (según el tamaño de los lápices).” (P11: F11 a LS CR AP 006.doc - 11:1 [Ponen todos al centro de la me..] (14:14))

Los registros verbales recogidos de observaciones y los registros visuales (videos) muestran una construcción lógica fundamental basada en el principio de causalidad. La característica predominante es el contexto determinado por el principio de "identidad" $(A=B)$ que permite transferir estas formas a regiones ónticas sin establecer las diferencias (entes reales, ideales, imaginarios, p.e.). Se aplican a cualquier contexto.

Esta característica aparece "naturalmente” en el niño, quien infiere causalmente las conclusiones sin establecer, por ejemplo, los contextos sociales y económicos. Esta identidad óntica, determinada por razones formales, permite explicar comportamientos "naturales” que chocan con las convenciones de una sociedad altamente jerarquizada. Este sometimiento a normas subyace en los consejos o en el castigo de los adultos o en la discriminación. Estas aplicaciones regulativas denotan un razonamiento normativo de los adultos que tiene implicaciones en la acción de los niños al "culturizarlos" para aceptar un orden impuesto históricamente por la sociedad.

En el siguiente ejemplo, se observa como la diferencia en el acceso a 
una golosina, determina a temprana edad, el conocimiento de las diferencias.

“Al nombrar a Josefina abre sus ojos y corre a alcanzar la brocheta, los que no tienen brochetas quedan mirando como comen los demás."

\section{P 4: F11 a LSC AP 004.doc - 4:9 [AI nombrar a Josefina abre sus ..]}

En el Jardín Infantil, normalmente los niños sacan galletas, dulces, frutas que están sobre la mesa. Si ven brochetas de frutas, entienden que están ahí para comerlas. Por lo tanto, pueden sacarlas. Siguiendo el razonamiento causal y sus expresiones lógicas del Modus Ponens, por ejemplo, tenderán a sacar las brochetas. Sin embargo, hay una normativa impuesta por los adultos. Si los padres no han pagado ('encargado') por ellas, la niña o niño no podrán disfrutar de ellas. Los niños ‘saben’ que si los padres no les han encargado brochetas de frutas, no pueden comer. Por eso, algunos comen y otros observan. Este conocimiento práctico de la diferencia a tan temprana edad marca el modo de pensar ya sea como una conclusión "natural" (resignada") o artificial determinada por el dinero. Estos principios regulativos se los impone la sociedad.

De acuerdo a estos registros, se obtiene como conclusión que el contexto semántico donde se enuncia el razonamiento, es muy importante porque determina la complejidad. Esto significa que, en un contexto de juego o de "normalidad infantil", los razonamientos aparecen libremente. El niño no está forzado a formular expresiones verbales de acuerdo a parámetros de adultos que controlan normativamente el hablar y el comportamiento. Asimismo el pensamiento complejo parece surgir originariamente de manera innata, como si la mente estuviera programada para realizar inferencias causales que adquieren formas de Modus Tollens o Modus Ponens, como casos formales específicos. La noción innata de la causalidad es generalizada en las observaciones. Está relacionada con la consistencia semántica de la experiencia sensorial de los niños. Esta particularidad formal y semántica choca con una lógica normativa proclive a las connotaciones históricas de las diferencias. 
Polis, Revista Latinoamericana, Volumen 13, $N^{\circ} 37,2014$

\section{Notas}

${ }^{1}$ Este artículo se ha escrito a partir del trabajo realizado en el Proyecto FONDECYT 110577: "Asombros educativos infantiles y propensión a aprender".

${ }^{2}$ Los nombres de los niños son ficticios con la finalidad de proteger sus identidades.

${ }^{3}$ Los entes imaginarios tienen las categorías de verosimilitud, intemporalidad, inespacialidad, vivencialidad 


\section{Bibliografía}

Lipman, M. (1991), Pensamiento complejo y educación. De la Torre. Madrid.

MKcCormack, T. S. (2013), "Blocking in children's causal learning depends on working memory and reasoning abilities” en Journal of Experimental Child Psychology, 1-8.

Salgado Sanhueza, J. (2012), Razonamientos de los niños. Informe de avance, La Serena, Chile.

Salgado, J., Calvo, C., \& Catalán, J. (1998), “Etnografía de la Etnografía” en Boletín de la Investigación Educacional (13), 341-355.

Recibido: 09.12.2013

Aceptado: 08.04.2014 